\title{
How the Interpretation of Drivers' Behavior in Virtual Environment Can Become a Road Design Tool: A Case Study
}

\author{
Marco Pasetto and Stefano Damiano Barbati \\ DCT, University of Padua, Via Marzolo 9, 35131 Padova, Italy \\ Correspondence should be addressed to Marco Pasetto, marco.pasetto@unipd.it \\ Received 28 October 2010; Revised 26 December 2010; Accepted 13 February 2011 \\ Academic Editor: Andreas Riener
}

Copyright (๑) 2011 M. Pasetto and S. D. Barbati. This is an open access article distributed under the Creative Commons Attribution License, which permits unrestricted use, distribution, and reproduction in any medium, provided the original work is properly cited.

\begin{abstract}
Driving is the result of a psychological process that translates data, signals and direct/indirect messages into behavior, which is continuously adapted to the exchange of varying stimuli between man, environment and vehicle. These stimuli are at times not perceived and at others perceived but not understood by the driver, even if they derive from tools (vertical signs, horizontal marking) specifically conceived for his safety. The result is unsafe behavior of vehicle drivers. For this reason, the road environment needs to be radically redesigned. The paper describes a research, based on real and virtual environment surveys, aimed to better understand drivers' action-reaction mechanisms inside different scenarios, in order to gain informations useful for a correct organization (design) of the road space. The driving simulator can help in developing, from road to laboratory, the study of new road design tools (geometrical, compositional, constructive ones, street furniture, etc.), because it can be used to evaluate solutions before their usefulness is proved on the road.
\end{abstract}

\section{Introduction}

Road safety is due to several factors that depend on the relationship between drivers, vehicle, road, and the surrounding environment. With regards to "drivers", safety is related to their behavior and risk perception at the moment in which the single action takes place $[1,2]$. The psychological elements that have repercussions on drivers' decision processes are connected to the emotional and sensory sphere; they may differ each time in relation to the subject and their personal motivations. In the same way, it can be observed that the behavior of the driver is influenced by the stimuli produced by the road, by the message arisen from the single stimulus, and by the willingness, capacity, and aptitude of the road user to process the message while driving $[3,4]$.

It is clear that humans are the main protagonist of driving, as they see, understand, recognize, interpret, evaluate, and make responsible (or irresponsible) choices. However, the surrounding environment, road platform inclusive, is not a passive scenery, because it continuously transmits to driver messages and signals that sometimes, for willful purposes, induce actions finalized to specific behaviors (e.g., respect of trajectory, limit speed, and defence of a right). For this reason, the road environment should be planned and designed in order to guide the user towards the most adequate and safe choices.

Two main ways (amid several intermediate options) exist for planning and designing the road environment: a theoretical way that prevalently considers the dynamics of the vehicle and its interaction with the external space and an empirical way, based on the analysis of experimental data and information collected in the real environment, concerning drivers' behaviors related to the road scenery driven through. Some attempts have been done with the purpose to merge the two approaches, in special way anticipating the experimental analysis to the step of theoretical design. This is made possible when the road layout is studied in a virtual environment, where not only the route can be reconstructed with all its components (platform, markings, signs, buildings, etc.), but also the behaviors can be simulated and a huge amount of data and information can be registered.

Several authors confirm that human behavior in a virtual environment can be considered sufficiently representative of reality $[5,6]$, particularly when its reconstruction is accurate 
[7]. "Immersive virtual reality" (i.e., the technology used in the research here described), in a specific way, has proved to be applicable to the reproduction of road environments, principally when perception and dynamic vision require to be studied under rigorous conditions that traditional simulators cannot guarantee.

Several studies have been developed in the field of cognitive psychology applied to road traffic. Some of these underline the role of perception as part of the process that allows the driver to define the level of safety while driving [8]. They assert that under conditions of normal visual acuteness, drivers have the disposition to give their car a trajectory which can be correctly adapted to the axis of the road lane, while otherwise behavior can be variable, particularly during the phase of recognition and initial approach to and exiting from curves $[9,10]$. The latter is an aspect that deserves to be carefully studied for its implications in traffic safety.

In order to complete these preliminary notes, there is a further consideration worth to be developed. The role of computer science (CS) in the engineering design is well known: it furnishes the instruments that permit to solve complex problems in a fast, correct, and generally exhaustive way. Advanced technologies based on CS can be used in different research topics, road design and traffic control included. The driving simulator (above mentioned) is a result of researches so conceived. However, it must be noticed that several studies have investigated alternative uses of CS, not only aimed at supporting the engineering design. In fact, some authors have particularly stressed the role of modern technologies in changing people's attitudes [11]. It has been demonstrated that computers and machines can be designed to influence human behaviors, positively bending the will by means of a persuasive action [12]. It is clear that a such point of view (captology) offers interesting potentialities in road design, where the "traditional" choice of the layout (on technical basis) is aimed to regulate drivers' behaviors but is not always sufficient in order to achieve this scope.

Within the framework of the mentioned current studies, this paper discusses the results of a research finalized to understand how the interpretation of drivers' behavior in a virtual environment (immersive type) could facilitate the identification of road design tools suitable for controlling the reaction of drivers under different environmental conditions. The authors have set up a multidisciplinary research project (supported by the Human Technologies Lab of the General Psychology Department of the same University), in order to extend the research on driving behavior to a virtual environment. The main objective was the laboratory reconstruction of a real road environment finalized to

(i) simulate the infrastructure stereoscopically,

(ii) virtually reproduce the real behavior,

(iii) monitor and compare real and virtual behavior,

(iv) understand the explicit and subliminal factors which influence driver behavior in both environments,

(v) study how the results from the virtual environment could be used in the real one, for a safer interaction between driver and road.
Driver behavior, after variations to the road layout, has been analyzed, studying the dynamic parameters of the motion, that is, vehicle operating speeds, accelerations, and decelerations, both in the daytime (under natural light) and at night (under artificial lighting), in the real and the virtual environment.

\section{The Virtual Environment}

For the reconstruction of the real environment in a virtual reality, the first basic objective was a cartographical reproduction of the study context. Surveys were used to define the exact planimetric map of buildings, fences, road verges, ditches, and other elements in the territory. When the twodimensional representation was complete, it was necessary to reconstruct the volumes of the buildings, the roadway, the bicycle lane along the south side of the road, courtyards, fields, ditches, trees, hurdles, lampposts, and vertical road signs. This was made possible thanks to appropriate software (Autocad, Adobe Photoshop, Autodesk 3DStudio.Max 8) used for a 3D reconstruction of the selected road link. Some simplifications were introduced in order to give manageable characteristics to the model. The animation was then added by means of software specifically conceived for driving simulators (Virtools).

Textures were also assigned to the objects, either by using photographs taken in the real environment or by assigning suitable colors to the areas of greenery and background, sky included (Figure 1). A model car was reproduced within the virtual environment, limited just to the dashboard, upper part of the steering-wheel, and front bonnet in order to reproduce real driving conditions as closely as possible. The car model chosen was a mid-range Mercedes (Figure 2). The decision to use a car existing on the market instead of a simple "ideal" model was made to render the driving test even more realistic.

After having calibrated the virtual model's characteristics on the basis of those recorded in the "physical" reality of the studied stretch of road, by exploiting the potentials of the virtual environment, five different driving scenarios were defined and reproduced, differing from one another by a single characteristic (independent variable). The five test environments were labeled from A to E, the first one (A) is corresponding entirely to the characteristics of the real environment, and the last $(\mathrm{E})$ is being constructed to include a substantial modification to the horizontal alignment of the route, through attenuating the bends.

The modifications introduced to the vertical road signs (driving scenario B) correspond to the application of the signs shown in Figure 3, positioned at a distance of $150 \mathrm{~m}$, $100 \mathrm{~m}$, and $50 \mathrm{~m}$ prior to entering the S-shaped double curve, in both directions of transit. The signs belong to the "perceptive" signs category (static, dynamic, and dynamicpunitive), the efficacy of which is documented in the literature [7].

The third environment $(\mathrm{C})$ introduced modifications to the horizontal road markings in terms of their retroreflection (night-time visibility) by the insertion of an optical marker 


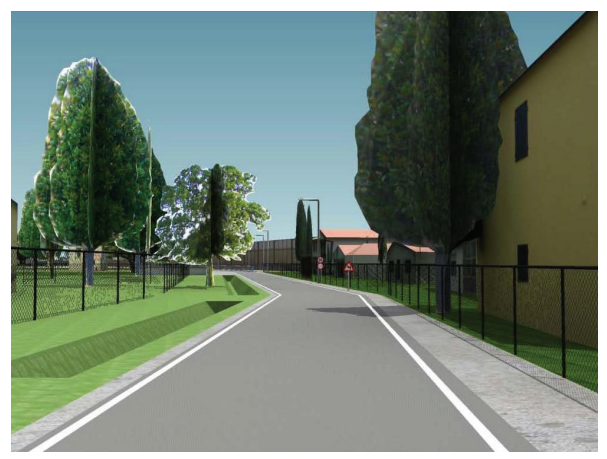

(a)

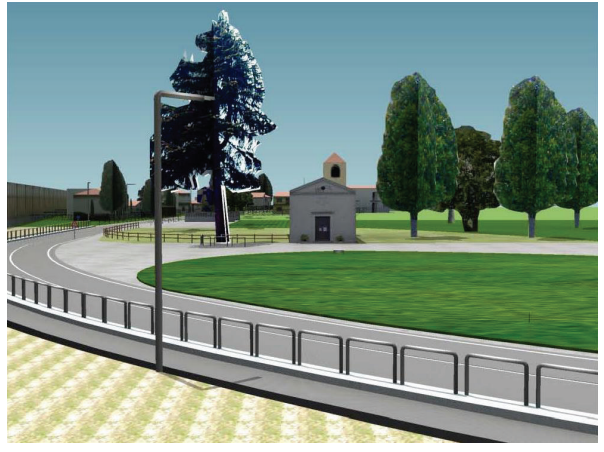

(b)

FIGURE 1: Details of the virtual environment.

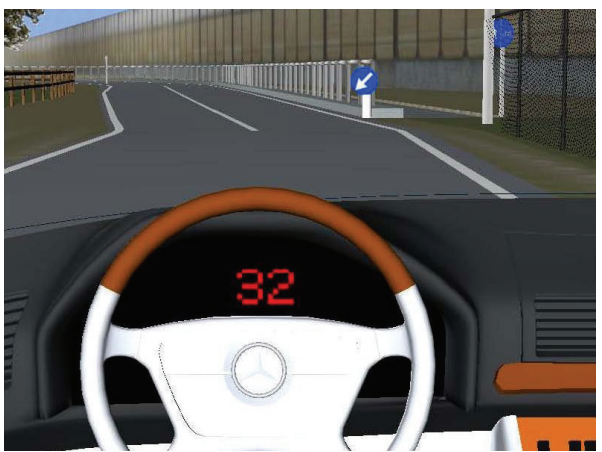

(a)

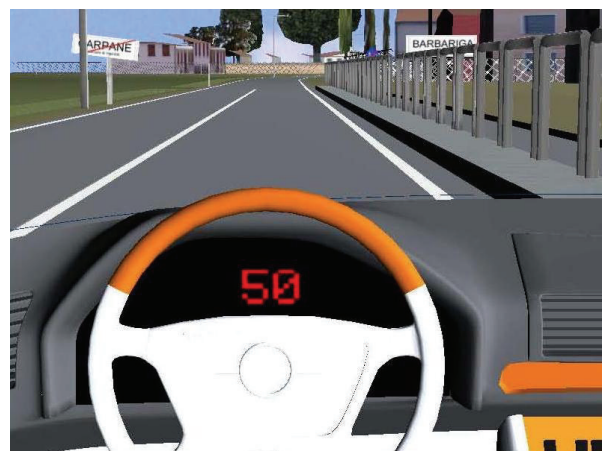

(b)

Figure 2: Details of the driving simulator.
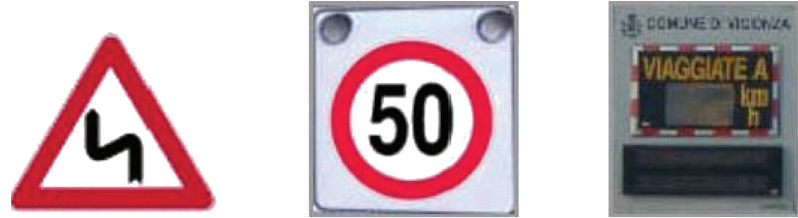

FIgURE 3: Types of vertical signs inserted in driving environment B.

TABLE 1: Synopsis of different scenarios analysed during the test.

\begin{tabular}{ll}
\hline Scenario & Description \\
\hline A & Real environment \\
B & A + vertical signs \\
C & A + horizontal marking \\
D & A + vertical signs + horizontal marking \\
E & Modified road layout \\
\hline
\end{tabular}

every $10 \mathrm{~m}$ along the lines delimiting the roadway and lanes [13]. Previous studies have demonstrated that the introduction of these markers can have an effect on drivers' attitude to speed on curvilinear stretches, as well as improving the perception of the planimetric geometry of the road axis $[14,15]$. The fourth scenario (D) was a combination of the situations B and C (Table 1).
The study was planned without considering interaction among vehicles, because of the variability of parameters, this can be introduced in the behavior of drivers.

\section{The Road Layout}

The road layout was selected keeping in mind the different factors that, accordingly to different authors, can influence driver behavior (number of lanes, road axis tortuousness, radius of circular curves, design parameters of clothoids, succession of straight stretches and curves, succession of curves' radii, road longitudinal and transverse gradient, composition and dimension of the road section, pavement texture and colour, presence of road barriers and street furniture, visibility, road signing and marking, lighting, etc.) $[10,16]$. The site was chosen in order to guarantee and include the highest number of critical factors.

The studied stretch of road is composed of two long straight sections to the east and west (Figure 4, Table 2), between which an S-shaped planimetric variant was recently introduced, with geometric-functional characteristics assimilable to those of type E "urban district" roads according to the Italian regulations in force.

The carriageway is composed of 2 lanes, and each one is $2.75 \mathrm{~m}$ wide on the straight stretch and $3.50 \mathrm{~m}$ on the Sshaped curve. The curvature radii of the design variant 


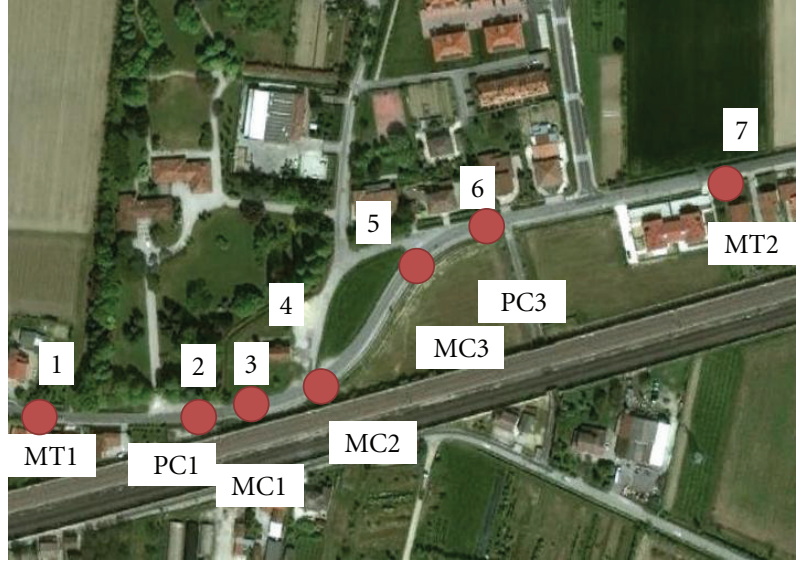

FIgURE 4: Road layout and geometrical characteristics.

TABLE 2: Geometrical characteristics of road layout elements.

\begin{tabular}{lcc}
\hline Road layout & Length $[\mathrm{m}]$ & Radius $[\mathrm{m}]$ \\
\hline Straight 1 & 166.3 & - \\
Curve 1 & 56.04 & 245.44 \\
Curve 2 & 83.90 & 96.49 \\
Transition curve & 26.20 & - \\
Curve 3 & 69.57 & 81.03 \\
Straight 2 & 404.60 & - \\
\hline
\end{tabular}

measure $96 \mathrm{~m}$ and $81 \mathrm{~m}$, respectively (from west to east). No transition curves (clothoids) were inserted.

The most interesting element of the stretch, from the point of view of behavior evaluation, is the presence of a new road intersection between sections 5 and 6 , which introduces an error in the perception of the route arriving from the east. This aspect is highlighted by Figure 5, where the intersection is represented from two different points of view, in real and virtual environment.

This is further aggravated by the position of the street lighting, which does not allow an efficient interpretation of the physiognomy of the route in night-time driving conditions. An evaluation of the efficacy of the present vertical road signs is also of great interest, as these are placed at points which are not very visible while driving. The distances of visibility are also very poor on the curvilinear stretch and such that the mutual visibility between vehicles entering the bends from either direction is not assured.

These elements were found to be critical during the experimental study conducted on the real road, the results of which made it possible to identify a set of design improvements, at both structural (planimetry of the road) and functional level (horizontal/vertical road signs), to be verified in the virtual environment.

\section{Real-Environment Survey}

The research has been organized in order to verify the validity of virtual reality in the field of road engineering, testingon the road and in the laboratory-the efficacy of some interventions aimed at improving safety. Moreover, the research intended to assess the capacity of drivers to adapt their behavior after environmental changes, brought about by means of explicit and unexplicit interventions. For this purpose, a stretch of road has been selected, suitable for counting and monitoring traffic without influencing the reaction of the drivers. The behaviors have been observed in terms of operating speed, acceleration/deceleration, and trajectories.

The initial phase of the project concerned the measurement of vehicles' speeds in the real-study context. The speed distribution curve of 4,215 vehicles was constructed for the daytime (up to 250 vehicles/hour) and that of 2,885 vehicles at night (up to 180 vehicles/hour). A team of volunteers (see Section 5) was also inserted in the real flow, in order to gather information useful for the following calibration of the laboratory tests at the driving simulator.

Traffic in the above-mentioned road sections was characterized by a level of service (LoS) equal to A, representative of a free flow of isolated vehicles. In order to adhere to the real situation, isolated vehicles were tested in the virtual environment too, in the total absence of moving objects (e.g., cars, trucks, people, and cycles). The speed of each vehicle was measured in the real environment with a tested procedure: a video camera was placed at the side of the road with the optic axle perpendicular to the trajectory. The camera was hidden from sight to avoid influencing driver behavior. It filmed a section of road, where two transversal lines had been traced across the carriageway $2.50 \mathrm{~m}$ apart (Figure 6).

For every vehicle, the back wheel was checked, and the time required to cross the two signs was used to calculate the speed $(v=\mathrm{s} / \mathrm{t})$. The camera has an internal clock with a precision of one second; in order to increase this precision, it was decided to make reference to the frequency of video frames, which is under $1 \mathrm{~s}$ according to the camera user's handbook. Accelerations and decelerations were calculated on the same basis. The "operating speed" of the amount of vehicles was defined: it is not the mean value of speeds, which is not considered significant in traffic engineering, but the 85th percentile of the measured speeds, in the daytime and at night, identified from their distribution curve (Figure 7).

The examined stretch of road was about $810 \mathrm{~m}$ in length. In order to mark out the required references for the calculation of the dynamic parameters of vehicles, 12 sections were located along it (Table 3 ). The stretch of road was monitored in the daytime and at night.

\section{Virtual Environment Test}

After the reconstruction of the real environment in the driving simulator, tests were performed in order to calibrate the virtual model. The drivers wore a helmet (HMD Virtual V8 Research type)—complete with headphones to receive the driving sound effects - to reproduce the real conditions in the immersive environment with stereoscopic vision. The testers were provided with a steering wheel, brake, and accelerator pedals, the sensitivity of which were calibrated to 


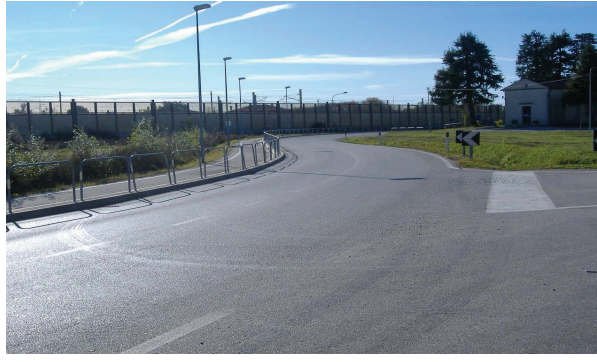

(a)

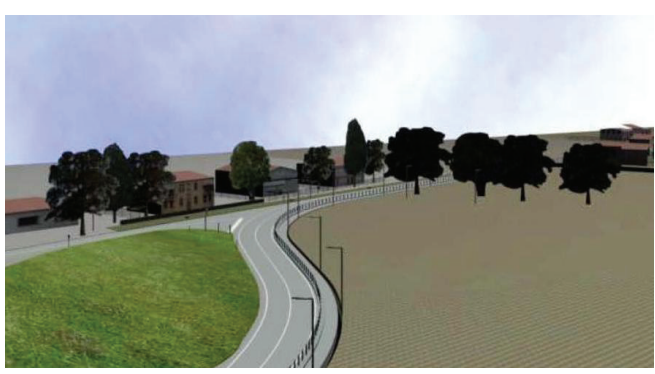

(b)

Figure 5: Real environment (westbound picture) and virtual environment (eastbound drawing): representation of the S-shape curve and the intersection.

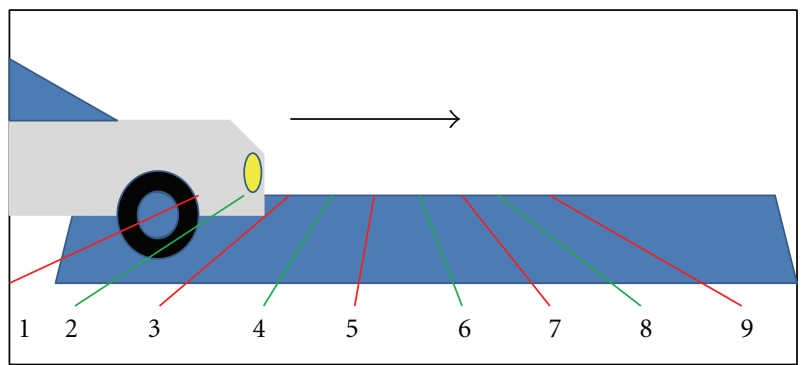

FIGURE 6: Characterization of vehicle speed.

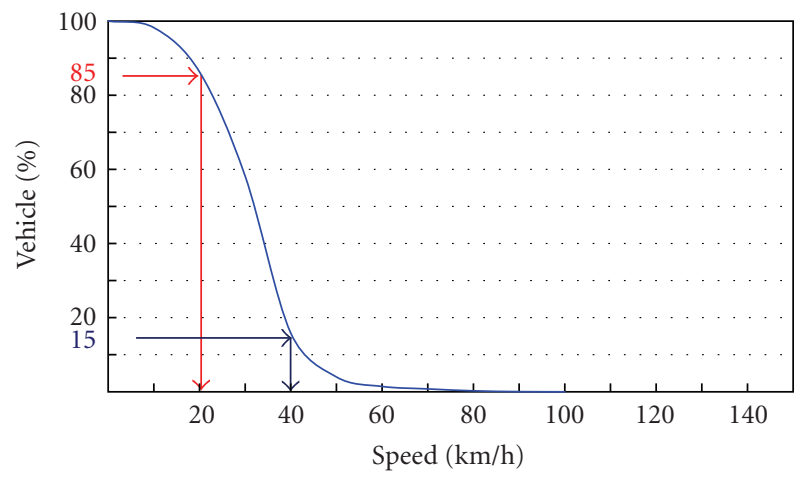

FIGURE 7: The operative speed is that speed which is not exceeded by the $85 \%$ of vehicles. In the diagram, that represents the distribution of velocities in a road section, the $100 \%$ of vehicles has a speed higher than $0 \mathrm{~km} / \mathrm{h}$; the $15 \%$ has a speed higher than $74 \mathrm{~km} / \mathrm{h}$. The operative speed is $74 \mathrm{~km} / \mathrm{h}$ (it belongs to $100 \%-15 \%$ of vehicles).

reproduce the real driving environment as closely as possible. For instance, the steering wheel (Logitech MOMO Racing Force Feedback Wheel type) was suitable for transmitting to the driver the dynamic (vibratory) effect of speed bumps, pot holes, road unevenness, and so forth. thanks to the technology of force feedback.

After having mastered the equipment in a training environment, a team of 60 volunteers was invited to drive along the test route in both directions, in the different scenarios. The volunteers were in the age range 24 to 33 years old (mean age 25.3 years, S.D. $=4.8$ ); $68.3 \%$ were males and $31.7 \%$ females. All the volunteers were informed about
TABLE 3: Road sections placing.

\begin{tabular}{lllc}
\hline Section & Name & \multicolumn{2}{c}{ Distance } \\
& & Partial $[\mathrm{m}]$ & Cumulative $[\mathrm{m}]$ \\
\hline 1 & - & 0.00 & 0.00 \\
2 & MT1 & 83.15 & 83.15 \\
3 & PC1 & 83.15 & 166.30 \\
4 & MC1 & 28.02 & 194.32 \\
5 & - & 28.02 & 222.34 \\
6 & MC2 & 41.95 & 264.29 \\
7 & - & 41.95 & 306.24 \\
8 & - & 26.20 & 332.44 \\
9 & MC3 & 34.79 & 367.23 \\
10 & PC3 & 34.79 & 402.02 \\
11 & MT2 & 202.30 & 604.32 \\
12 & PT2 & 202.30 & 806.62 \\
\hline
\end{tabular}

the test, pointing out the necessity to relax and try to act as naturally as possible. Each volunteer had to drive in the five different environments, but the performances were mixed in order to minimize whichever expectation of novelty (the scenario B followed A, but it was not presented immediately after A: the driving of each volunteer was alternated with the others). Variables of the test were the 5 scenarios, the direction, and the period of the day during the simulation.

During the test, the model registered the speed, acceleration, breaking, and instantaneous spatial coordinates of each driver, to be used in the successive kinematic study of the behavior in relation to the different inputs.

After calibration of the virtual model on the basis of the real data acquired during the previous phase (realenvironment survey), five different driving scenarios were developed in the virtual environment, in order to verify the efficacy of the different changes to be introduced in the test (see Section 2). The calibration was based on the comparison between the driving parameters of the real traffic and the same parameters registered during the testing in the initial scenario A, which was the reproduction of the real environment. The evaluation of the virtual environment was performed in 4 different road sections by means of speed and acceleration. 
TABLE 4: Operating speed $\left(\mathrm{S}_{85}, \mathrm{~km} / \mathrm{h}\right)$ measured in daytime and at night, in the real and virtual environments, eastwards (a) and westwards (b).

(a)

\begin{tabular}{lllll}
\hline \multirow{2}{*}{ Description } & \multicolumn{3}{c}{ Real } & \multicolumn{2}{c}{ Virtual } \\
& Day & Night & Day & Night \\
\hline MT1 & 76.50 & 78.30 & 73.65 & 75.00 \\
PC1 & 73.50 & 77.50 & 72.50 & 72.35 \\
MC1 & 61.88 & 58.70 & 62.35 & 53.00 \\
MC2 & 60.06 & 44.53 & 62.95 & 47.35 \\
MC3 & 56.25 & 47.26 & 59.25 & 48.00 \\
PC3 & 58.50 & 49.30 & 59.60 & 52.35 \\
MT2 & 60.13 & 49.60 & 60.45 & 54.00 \\
PT2 & 75.00 & 77.50 & 75.30 & 74.00 \\
\hline
\end{tabular}

(b)

\begin{tabular}{lllll}
\hline \multirow{2}{*}{ Description } & \multicolumn{3}{c}{ Real } & \multicolumn{2}{c}{ Operating Speed [km/h] } \\
& Day & Night & Day & Night \\
\hline MT1 & 69.79 & 70.30 & 66.90 & 68.35 \\
PC1 & 60.00 & 62.40 & 61.30 & 57.70 \\
MC1 & 59.70 & 52.70 & 59.85 & 51.35 \\
MC2 & 58.50 & 51.50 & 58.25 & 51.00 \\
MC3 & 59.20 & 53.20 & 58.55 & 50.35 \\
PC3 & 60.20 & 55.20 & 61.50 & 56.35 \\
MT2 & 70.31 & 69.40 & 69.15 & 72.30 \\
PT2 & 72.00 & 71.30 & 72.55 & 75.40 \\
\hline
\end{tabular}

\section{Results}

A statistical analysis has been performed in order to identify the factors which can influence drivers' behavior. The evaluation has been limited to the reference sections but extended to the different scenarios and driving conditions. For each situation, the statistical profile has been defined (mean, standard deviation, quartiles, and percentiles), but the attention was put on the parameter commonly used in literature, that is, the 85 th percentile. In any case, for the analyzed cases, Student's $t$-test (alpha 0.05 , bilateral) has been carried out in order to discriminate the secondary factors from those really conditioning drivers' behaviors.

The first scenario (A) reproduces the real environment. It was also used for the calibration of the virtual model. Figures 8 and 9 compare speeds in both directions of travel, during the daytime and at night, in the real and virtual environment. As previously mentioned, the test results are reported in terms of the value of the operating speed. The results are also summarized in Table 4.

The first objective of the research was the construction of a virtual model as similar as possible to the real one. The reference parameter was the "speed profile", given by the operating speed (i.e., the 85 th percentile of speed, $\mathrm{S}_{85}$ ). The operating speed registered during virtual tests was not only usually higher than the legal speed limit $(50 \mathrm{~km} / \mathrm{h}$, except for 2 sections, MC2 and MC3, in the westbound direction) but also higher than the real speed. During the day, eastbound speeds of between 58.25 and $72.55 \mathrm{~km} / \mathrm{h}$ were recorded; in the opposite direction, speeds were within the range 59.25 to $77.30 \mathrm{~km} / \mathrm{h}$. During the night, the eastbound speed increased to between 50.35 and $75.40 \mathrm{~km} / \mathrm{h}$, while the westbound speed varied between 47.35 and $75.00 \mathrm{~km} / \mathrm{h}$.

As concerns the speeds measured on site, during the real observations, $15 \%$ of the eastbound vehicles exceeded the speed limits both in the daytime $(58.50 \mathrm{~km} / \mathrm{h}$ to $72.00 \mathrm{~km} / \mathrm{h})$ and at night $(51.50 \mathrm{~km} / \mathrm{h}$ to $71.30 \mathrm{~km} / \mathrm{h})$. In the opposite direction (westbound), the operating speed in the daytime was still above $50 \mathrm{~km} / \mathrm{h}(56.25 \mathrm{~km} / \mathrm{h}$ to $76.50 \mathrm{~km} / \mathrm{h})$, while at night, near the S-shaped alignment, a noticeable reduction was observed $(44.53 \mathrm{~km} / \mathrm{h}$ to $49.60 \mathrm{~km} / \mathrm{h})$, with a few exceptions.

In terms of acceleration, it was noted at the simulator that in the daytime, the maximum eastbound deceleration was $-0.21 \mathrm{~m} / \mathrm{s}^{2}$ (PC1 section); maximum acceleration was $0.59 \mathrm{~m} / \mathrm{s}^{2}$ (MT2 section). At night, the maximum values of deceleration and acceleration were $-0.40 \mathrm{~m} / \mathrm{s}^{2}$ and $1.24 \mathrm{~m} / \mathrm{s}^{2}$, respectively. In the opposite direction (westbound), in the daytime, the results were very similar in the real and virtual environments: maximum deceleration (in the PC3 section) was $-0.93 \mathrm{~m} / \mathrm{s}^{2}$, while maximum acceleration (MT1 section) was $0.59 \mathrm{~m} / \mathrm{s}^{2}$. At night, the maximum values of deceleration/acceleration were observed in the sections PC3 $\left(-1.55 \mathrm{~m} / \mathrm{s}^{2}\right)$ and MT1 $\left(0.79 \mathrm{~m} / \mathrm{s}^{2}\right)$.

In the real environment, in the daytime, the maximum eastbound deceleration observed was $-0.37 \mathrm{~m} / \mathrm{s}^{2}$ (second section and between sections MT1 and PC1); maximum acceleration was $0.78 \mathrm{~m} / \mathrm{s}^{2}$ (near PC3-MT2). During the night, the maximum values of deceleration and acceleration occurred on the same sections listed above and were $-0.30 \mathrm{~m} / \mathrm{s}^{2}$ and $1.10 \mathrm{~m} / \mathrm{s}^{2}$, respectively. In the opposite direction, maximum deceleration (section PC3) in the daytime was $-0.93 \mathrm{~m} / \mathrm{s}^{2}$, while maximum acceleration was $0.59 \mathrm{~m} / \mathrm{s}^{2}$ (final section MT1). At night, the maximum values of acceleration were $-2.66 \mathrm{~m} / \mathrm{s}^{2}$ (PC3 section) and $1.10 \mathrm{~m} / \mathrm{s}^{2}$ (MT1).

In the second phase of the research, some variations were made to the road environment. An exact comparison was possible between virtual and real environment when changes could be made on the road (e.g., with vertical signs); in other situations that could not be reproduced (new horizontal alignment), the driving simulator was used to predict the effect of possible changes. In either case, the operating speeds, accelerations, and decelerations were used as reference parameter (Figure 10).

The test performed eastbound in the daytime shows homogeneous behavior in all the scenarios, the operating speed varying within a range of $5 \%$ of the mean value. The only difference worth mentioning is related to scenario E, the only one with geometric variations. In this case, behaviors are marked by a more stable and less jerky approach to the curvilinear element, despite the higher mean speed and lower acceleration/deceleration than in the other test environments. In daytime conditions, changes to vertical 


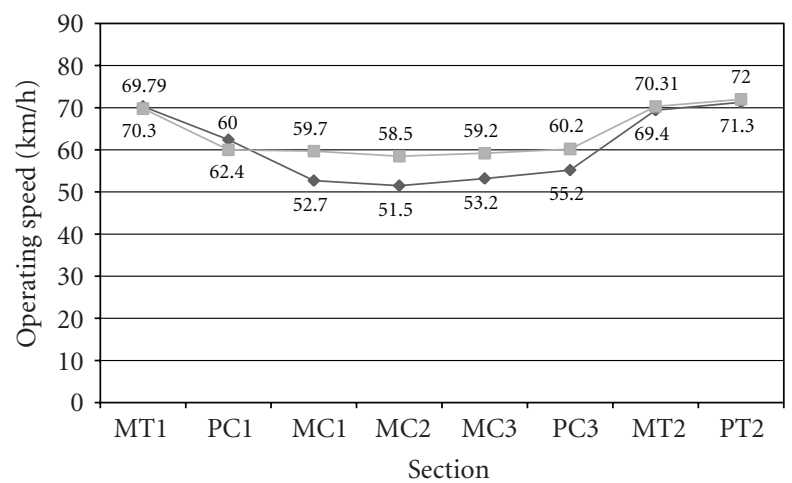

$\rightarrow$ Night

- Day

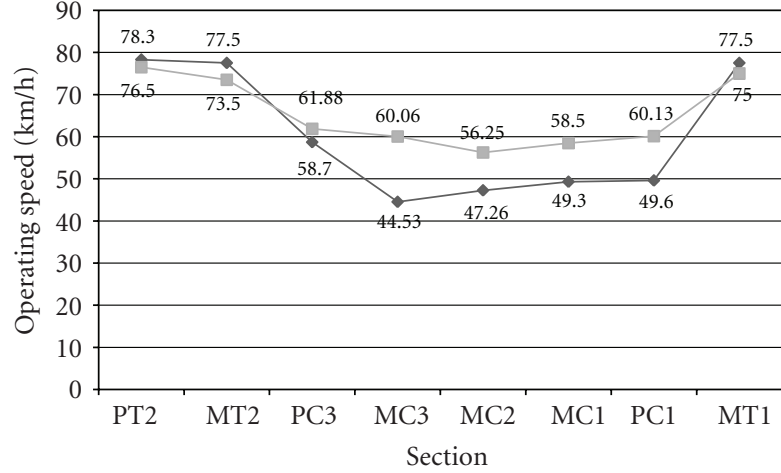

$\rightarrow$ Night

- Day

(a)

(b)

FIGURE 8: Night/day operating speed $\left(\mathrm{S}_{85}, \mathrm{~km} / \mathrm{h}\right)$, eastwards (a) and westwards (b), in real environment.

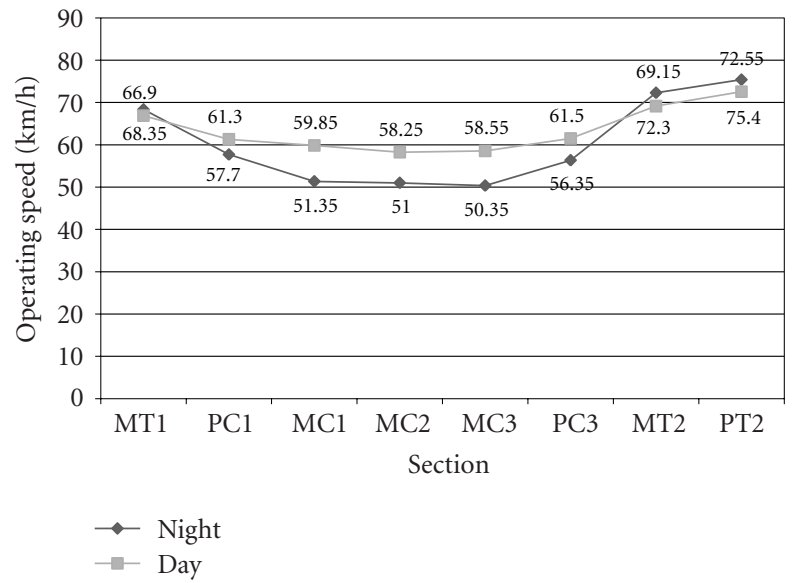

(a)

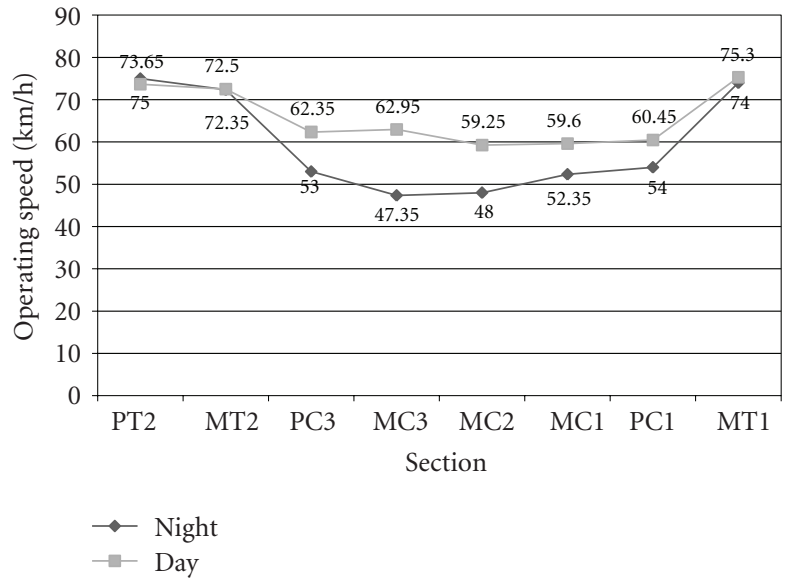

(b)

FIGURE 9: Night/day operating speed $\left(S_{85}, \mathrm{~km} / \mathrm{h}\right)$, eastwards (a) and westwards (b), in virtual environment.

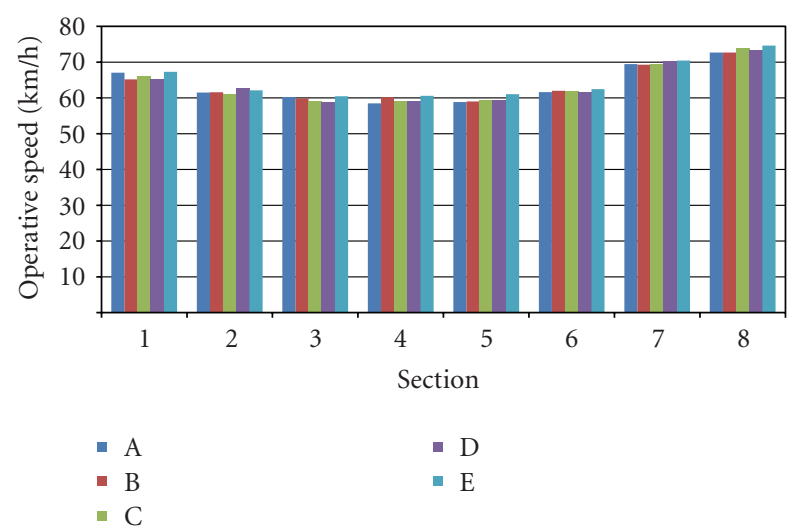

Figure 10: Speed profile in 5 different driving environments in the eastbound direction. Scenarios A (present layout), B (A + vertical signs), C (A + horizontal marking), D (A + signs + marking), and E (layout modified). road signs and horizontal road markings also appear to have no substantial effect.

In the opposite direction (westbound), a marked dissimilarity in the approach to the S-shaped curve can be observed: the introduction of vertical warning signs and the placing of optical markers translates into a greater adjustment of the speed selected approaching the curve, followed by a more stable driving behavior along the entire length of the S-bend.

The geometric modification of the layout (scenario E) provides an improvement in terms of legibility of the road, as demonstrated by the graph in Figure 11, which reports the partial accelerations/decelerations between successive control sections, referred to the 85th percentile of the distribution of recorded accelerations. Even if higher speeds are usually noticed because of more homogeneous properties of the geometric elements which form the road layout, lower variations in the dynamic parameters (acceleration, deceleration) are registered. 


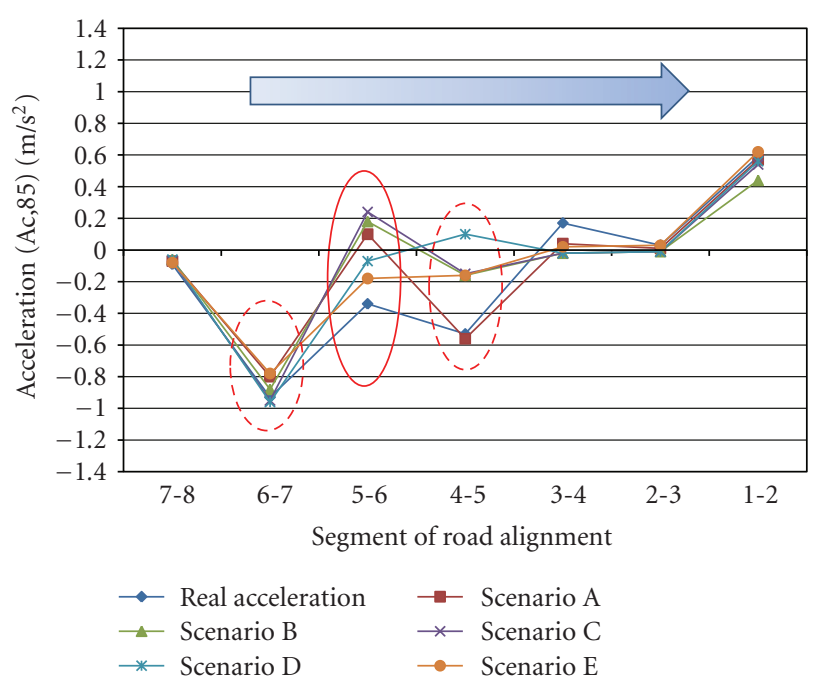

Figure 11: Profile of the accelerations in the different driving environments, westbound direction.

For a better comparison among the scenarios, a statistical analysis was carried out by means of matrices of probability of mutual influence. Table 5 reports, as an example, the matrix related to MT1 section, where each value represents the probability that the difference in speed values could not be due to the variation of factors but to the statistic case. In the matrices, the number of variables to be considered can be elevated, but in such a case, a high number of samples is necessary.

For instance, in the daytime, from MT1 to PT2 section (eastwards), with and without vertical signs, a probability of $42 \%(P=.42)$ that a difference between speeds could be referred either to other concomitant causes or to casualness is expected. At night, there is a high probability that a difference in speeds could be due to several factors different from the lack of signs. In the opposite direction (westwards), the probability of a dependence between the difference on measured speeds and the variation of considered factors diminishes $(P>.05)$.

The analysis of the matrix of influences gives the conclusion that in the virtual environment the conditioning effect related to the different visibility conditions (day, night) prevails on the presence of vertical signing.

Table 6 shows some extreme situations, where a probability of connection among the different factors was close to $100 \%$, demonstrating that a difference of measured speeds is not depending on the variation of the considered factors. It happens westwards, in the MC2 section, inside the S-shape curve. In the daytime, there is no dependence between speed variations and signing presence $(P=.925)$, as well as in the case of contemporary variation of signing and visibility in the daytime and at night $(P=.818)$.

Finally, as regards the role of the type of vertical signing, it can be mentioned that in the real environment as well as in the virtual one, static signs are not always perceived, because they are confused with the background and often considered as simple "furnishings"; they do not produce any effective coercion, as stated by the profiles of speed and acceleration. Dynamic (intermittent) lighting combined with the vertical signs is more efficacious and determines more uniform driving behavior, attracting the attention of the road users to the geometrical characteristics of the road layout. The best result is guaranteed by the dynamic message, which recalls the speed limit together the real speed and the subsequent penalization to the driving licence because of illegal behaviors.

\section{Discussion and Conclusions}

The study of drivers behavior in a virtual environment for road design purposes is a research field which is sometimes not accepted due to factors of visual technology and environmental reconstruction. However, it can be demonstrated that the driving simulator is not only a laboratory tool useful for reproducing the trajectory of vehicles in a road environment in a dynamic way, but also an instrument that can forecast drivers' behavior in different situations. During several tests in different scenarios, a statistical comparability has been verified between speeds measured in both the virtual and real environment.

Along a road stretch, where the traffic was monitored in both directions by means of operating speed and dynamic parameters, it was observed that the succession of geometric elements in the road layout determines various behaviors and drivers' different choices both in the daytime and at night. The most important aspect is the quite good correspondence between real and laboratory behavior, vehicle speed, acceleration, and deceleration being very similar in both cases. The simulator proves to be useful in the representation of real behavior, but also it can become a design instrument because it can forecast the effects of road modifications before they are carried out (this aspect was accurately checked in real and virtual environment). With the reproduction of real environments in the laboratory, all design choices can be simulated, corrected, modified, and refined in a fast cyclic process that does not require expensive works and adjustments; thus, a preliminary study can avoid in situ experimentation.

The simulator allows detailed information to be acquired on the behavior of road users (accelerations, breaking, instantaneous speed, and trajectories) that cannot always be measured in reality, so it becomes a valid instrument for the evaluation of interventions aimed at improving road safety, such as modifications to road signs, geometry, or the driving environment in a more general sense.

A limitation to applications in the road sector regards the oversimplification of the dynamic characteristics of the vehicle model, in terms of inertia and destabilizing forces while driving (especially on a curve), which unavoidably alter the information on driving behavior with respect to the corresponding real environment. On the other hand, a good result is that the simplification of the environment near the road does not appear to be relevant to driver behavior so that more precise representations are not necessary. 
TABLE 5: MT1 section. Matrix of probability of mutual influence among environmental factors.

\begin{tabular}{|c|c|c|c|c|c|c|c|c|}
\hline & $\begin{array}{l}\text { Day, eastw. } \\
\text { yes sign }\end{array}$ & $\begin{array}{l}\text { Night, eastw. } \\
\text { yes sign }\end{array}$ & $\begin{array}{l}\text { Day, eastw. } \\
\text { no sign }\end{array}$ & $\begin{array}{l}\text { Night, eastw. } \\
\text { no sign }\end{array}$ & $\begin{array}{l}\text { Day, westw. } \\
\text { yes sign }\end{array}$ & $\begin{array}{l}\text { Night, westw. } \\
\text { yes sign }\end{array}$ & $\begin{array}{l}\text { Day, westw. } \\
\text { no sign }\end{array}$ & $\begin{array}{l}\text { Night, westw. } \\
\text { no sign }\end{array}$ \\
\hline Day, eastw. yes sign & & 0.001 & 0.420 & 0.007 & 0.007 & 0.000 & 0.005 & 0.000 \\
\hline Night, eastw. yes sign & & & 0.001 & 0.699 & 0.716 & 0.253 & 0.264 & 0.490 \\
\hline Day, eastw. no sign & & & & 0.007 & 0.002 & 0.001 & 0.003 & 0.001 \\
\hline Night, eastw. no sign & & & & & 0.549 & 0.442 & 0.336 & 0.765 \\
\hline Day, westw. yes sign & & & & & & 0.171 & 0.436 & 0.341 \\
\hline Night, westw. yes sign & & & & & & & 0.066 & 0.225 \\
\hline Day, westw. no sign & & & & & & & & 0.036 \\
\hline Night, westw. no sign & & & & & & & & \\
\hline
\end{tabular}

TABLE 6: MC2 section. Matrix of probability of mutual influence among environmental factors.

\begin{tabular}{|c|c|c|c|c|c|c|c|c|}
\hline & $\begin{array}{l}\text { Day, eastw. } \\
\text { yes sign }\end{array}$ & $\begin{array}{l}\text { Night, eastw. } \\
\text { yes sign }\end{array}$ & $\begin{array}{l}\text { Day, eastw. } \\
\text { no sign }\end{array}$ & $\begin{array}{l}\text { Night, eastw. } \\
\text { no sign }\end{array}$ & $\begin{array}{l}\text { Day, westw. } \\
\text { yes sign }\end{array}$ & $\begin{array}{l}\text { Night, westw. } \\
\text { yes sign }\end{array}$ & $\begin{array}{l}\text { Day, westw. } \\
\text { no sign }\end{array}$ & $\begin{array}{l}\text { Night, westw. } \\
\text { no sign }\end{array}$ \\
\hline Day, eastw. yes sign & & 0.062 & 0.130 & 0.033 & 0.854 & 0.031 & 0.811 & 0.053 \\
\hline Night, eastw. yes sign & & & 0.002 & 0.170 & 0.001 & 0.565 & 0.095 & 0.499 \\
\hline Day, eastw. no sign & & & & 0.002 & 0.015 & 0.004 & 0.013 & 0.000 \\
\hline Night, eastw. no sign & & & & & 0.001 & 0.736 & 0.046 & 1.000 \\
\hline Day, westw. yes sign & & & & & & 0.002 & 0.925 & 0.002 \\
\hline Night, westw. yes sign & & & & & & & 0.818 & 0.093 \\
\hline Day, westw. no sign & & & & & & & & 0.042 \\
\hline Night, westw. no sign & & & & & & & & \\
\hline
\end{tabular}

Some minor differences have been noticed in the speed and acceleration/deceleration profiles between real and virtual environment, mainly due to a relaxation in the latter because of the implicit certainty of safety in the test (no "surprises" were expected). Moreover, the volunteers, being aware of participating in a trial, paid more attention to the road environment. For this reason, the model is being developed and completed by the insertion of external agents that could provide variety to enliven the virtual trip.

In regard to the trajectories at the simulator, they appeared to be closely related to each scenario. Little difference was possible for "badly designed" roads (scenario A), and minimum differences were recorded in the scenarios improved by road signs and markings. This demonstrates that the virtual model is not only reliable for reproducing the road layout, but also that it can be used in the experimentation of new solutions to improve the safety of vehicles.

The test conducted on the legibility of the road environment by means of the insertion of signs and markings (on the road and at the simulator) has demonstrated their role on safety but also that their persuasiveness is highly variable. Particularly, a statistical analysis and the definition of matrices of probability of mutual influence has given evidence to the fact that usually, vertical signing do not influence in significant manner the speed along the most critical sections (inside the S-shape curve), unless the signs point out the risk of being fined by the police, as a consequence of breaking the law.
In practice, the study puts in evidence when and how the road environment can really be changed in order to become more persuasive for the road users. The virtual environment has the potential to ascertain to what degree this can be done.

\section{References}

[1] G. Kaintheidis, A. Zervas, and V. Karagioules, "Drivers risk perception of road design elements," Transportation Human Factors, vol. 2, no. 1, pp. 39-48, 2000.

[2] F. P. McKenna, "Drivers' perception of risk," Accident Analysis and Prevention, vol. 23, pp. 45-62, 1991.

[3] H. Shinoda, M. M. Hayhoe, and A. Shrivastava, "What controls attention in natural environments?" Vision Research, vol. 41, no. 25-26, pp. 3535-3545, 2001.

[4] M. Mohan, Seeing, Doing, and Knowing: A Philosophical Theory of Sense Perception, Clarendon Press, Oxford, UK, 2005.

[5] S. Nikiel, "Realism vs. reality: creating virtual reconstructions of architectural artifacts," in Proceedings of the 10th Annual International Workshop on Presence, pp. 359-388, Barcelona, Spain, 2007, (Poster Session 2).

[6] K. Patel, J. Bailenson, S. H. Jung, R. Diankov, and R. Bajcsy, "The effects of fully immersed virtual reality on the learning of physical tasks," in Proceedings of the 8th Annual International Workshop on Presence, pp. 129-138, Cleveland, Ohio, USA, 2006.

[7] Y. A. W. Slangen-de Kort, W. A. Ijsselsteijn, J. Kooijman, and Y. Schuurmans, "Virtual environments as research tools for environmental psychology: a study of the comparability of real 
and virtual environments," in Proceedings of the 4th Annual International Workshop on Presence, Philadelphia, Pa, USA, 2001.

[8] C. Castro, Human Factors of Visual and Cognitive Performance in Driving, CRC Press, Taylor \& Francis, Boca Raton, Fla, USA, 2009.

[9] J. O. Brooks, R. A. Tyrrell, and T. A. Frank, "The effects of severe visual challenges on steering performance in visually healthy young drivers," Optometry and Vision Science, vol. 82, no. 8, pp. 689-697, 2005.

[10] M. Pasetto, L. Gamberini, and A. Manganaro, "Potential of immersive virtual reality models in studies of drivers' behaviour and interventions to improve road safety," in Presence Conference Workshop, Padova, Italy, October, 2008.

[11] B. J. Fogg, Persuasive Technology: Using Computers to Change What We Think and Do, Morgan Kaufmann, 2002.

[12] B. J. Fogg, "Captology: the study of computers as persuasive technologies," in Proceedings CHI '97, Human Factors in Computing Systems: Looking to the Future, ACM, New York, NY, USA, 1997.

[13] European Commission, Directorate General Transport, COST 331 Requirements for Horizontal Road Markings, Office for Official Publications of the European Communities, Luxembourg, UK, 1999.

[14] S. G. Charlton, "Perceptual and attentional effects on drivers' speed selection at curves," Accident Analysis and Prevention, vol. 36, no. 5, pp. 877-884, 2004.

[15] S. G. Charlton, "The role of attention in horizontal curves: a comparison of advance warning, delineation, and road marking treatments," Accident Analysis and Prevention, vol. 39, no. 5, pp. 873-885, 2007.

[16] E. D. Dickmanns, Dynamic Vision for Perception and Control of Motion, Springer, London, UK, 2007. 

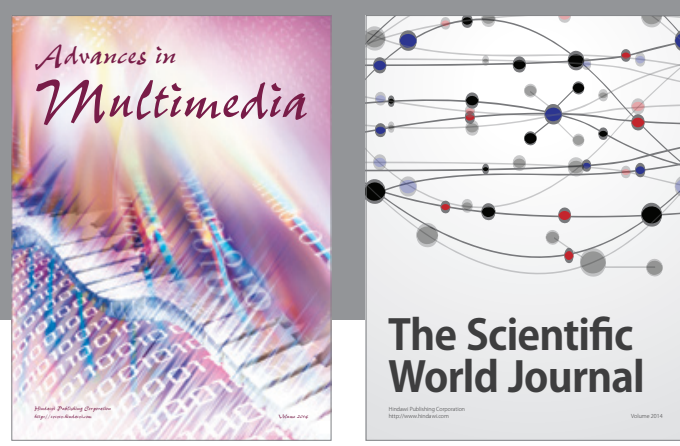

The Scientific World Journal
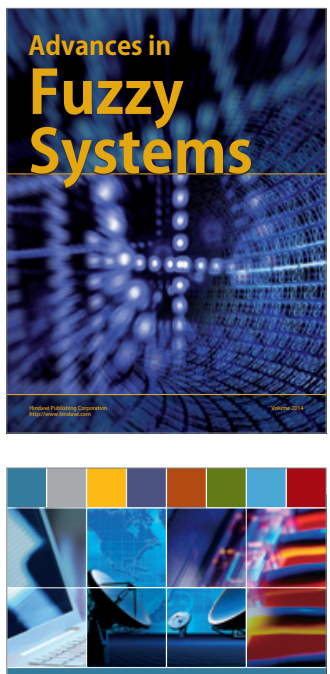

Computer Networks and Communications
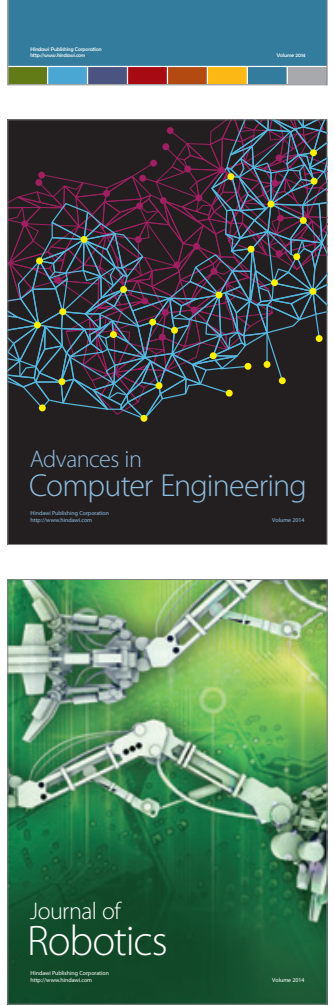
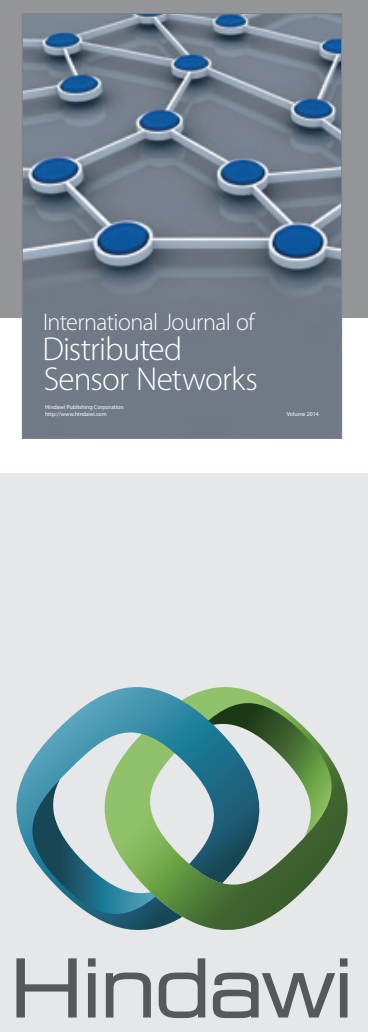

Submit your manuscripts at

http://www.hindawi.com
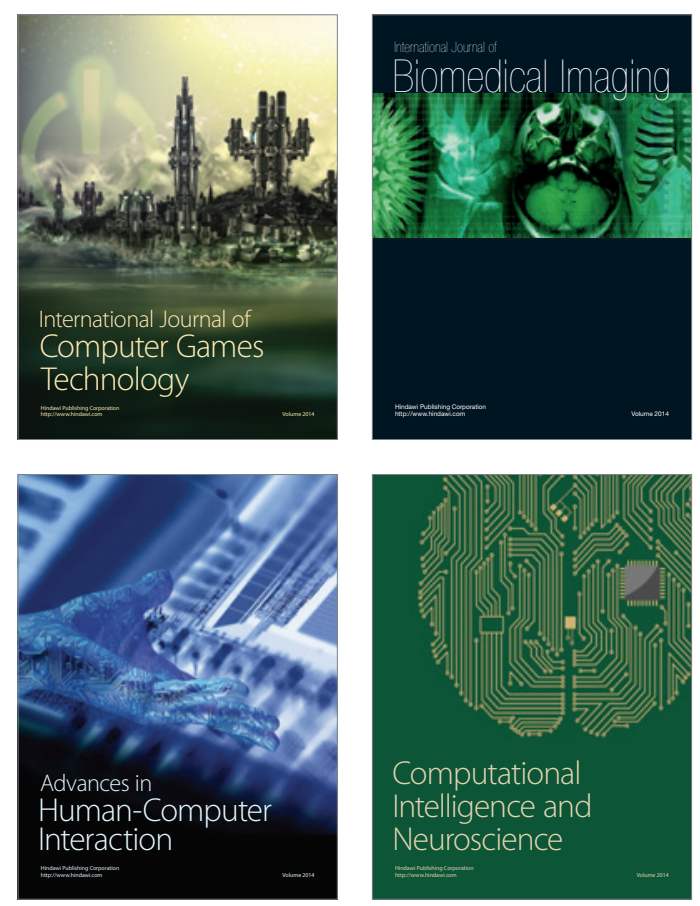
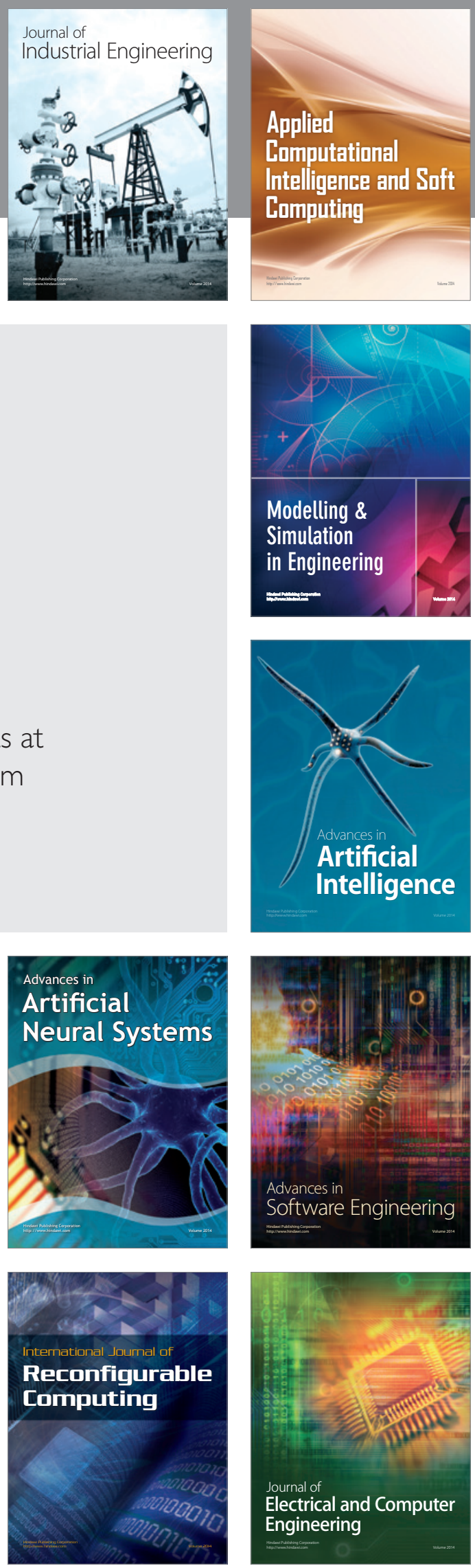